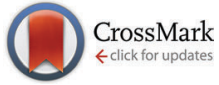

Cite this: Mol. BioSyst., 2014, 10, 2724

Received 18th June 2014, Accepted 22nd July 2014

DOI: $10.1039 / c 4 m b 00359 d$

www.rsc.org/molecularbiosystems

\title{
Diminazene or berenil, a classic duplex minor groove binder, binds to G-quadruplexes with low nanomolar dissociation constants and the amidine groups are also critical for G-quadruplex binding
}

\author{
Jie Zhou, ${ }^{a}$ Vu Le, ${ }^{b}$ Dimpy Kalia, ${ }^{a}$ Shizuka Nakayama, ${ }^{a}$ Clinton Mikek, ${ }^{b}$ \\ Edwin A. Lewis ${ }^{\star b}$ and Herman O. Sintim ${ }^{\star a c}$
}

\begin{abstract}
G-quadruplexes have shown great promise as chemotherapeutic targets, probably by inhibiting telomere elongation or downregulating oncogene expression. There have been many G-quadruplex ligands developed over the years but only a few have drug-like properties. Consequently only a few G-quadruplex ligands have entered clinical trials as cancer chemotherapeutic agents. The DNA minor groove ligand, berenil (diminazene aceturate or DMZ), is used to treat animal trypanosomiasis and hence its toxicological profile is already known, making it an ideal platform to engineer into new therapeutics. Herein, using a plethora of biophysical methods including UV, NMR, MS and ITC, we show that DMZ binds to several G-quadruplexes with a $K_{\mathrm{d}}$ of $\sim 1 \mathrm{nM}$. This is one of the strongest G-quadruplex binding affinities reported to date and is $10^{3}$ tighter than the berenil affinity for an AT-rich duplex DNA. Structure-activity-relationship studies demonstrate that the two amidine groups on DMZ are important for binding to both G-quadruplex and duplex DNA. This work reveals that DMZ or berenil is not as selective for AT-rich duplexes as originally thought and that some of its biological effects could be manifested through G-quadruplex binding. The DMZ scaffold represents a good starting point to develop new G-quadruplex ligands for cancer cell targeting.
\end{abstract}

\section{Introduction}

Both DNA and RNA can form many secondary structures, such as G-quadruplex, ${ }^{1-3}$ triplex, $^{4,5}$ i-motif, ${ }^{6,7}$ and a biological role for these polymorphs, especially G-quadruplexes, ${ }^{8-10}$ has been suggested. There are $\sim 3760000$ guanine-rich regions in the human genome, which have the potential to form G-quadruplexes, ${ }^{11,12}$ including those at the telomere end ${ }^{13}$ and promoter regions of some cancer-related genes. ${ }^{10}$ Guanine tracts in RNA are known to form G-quadruplexes in vivo ${ }^{3,14-16}$ but the formation of G-quadruplexes in chromosomal DNA has been a matter of debate

\footnotetext{
${ }^{a}$ Department of Chemistry and Biochemistry, University of Maryland, College Park, MD 20742, USA. E-mail: hsintim@umd.edu

${ }^{b}$ Department of Chemistry, Mississippi State University, Mississippi State,

MS 39762, USA. E-mail: elewis@chemistry.msstate.edu

${ }^{c}$ Program in Oncology, University of Maryland Marlene and Stewart Greenebaum Cancer Center, 22 S. Greene Street, Baltimore, Maryland 21201, USA

$\dagger$ Electronic supplementary information (ESI) available: Competition assay between DMZ and NMM for G-quadruplex binding, UV titration studies of DNA with DMZ and Triazene-1, CD spectra of DMZ and Triazene-1 binding to duplex DNA and NMR spectra of Triazene- 1 and Triazene- 2 are available. ITC raw data for the DMZ and Triazene- 1 titrations of the HP and G-quadruplex DNAs. See DOI: $10.1039 / \mathrm{c} 4 \mathrm{mb} 00359 \mathrm{~d}$
}

due to the fact that the guanine tracts in chromosomal DNA can also form duplexes with complementary tracts of cytosines. After many years of fierce debate regarding a biological role for DNA G-quadruplexes in vivo, acceptance is now growing that DNA G-quadruplexes might indeed form in vivo and that there could be biological consequences of G-quadruplex formation in chromosomal DNA. Firstly, it has been demonstrated that fluorogenic G-quadruplex-specific ligands could become fluorescent inside cells, especially during cell division, when single stranded regions of chromosomal DNA are created during DNA replication. ${ }^{17,18}$ Secondly, seminal works by the laboratories of Pluckthun ${ }^{19}$ and Balasubramanian $^{20}$ resulted in the engineering of G-quadruplexspecific antibodies, which have been used to provide compelling evidence that G-quadruplexes form in vivo. Additionally, biophysical approaches (mainly $\mathrm{NMR}^{21,22}$ and DEER/ENDOR ${ }^{23,24}$ ) have demonstrated that synthetic G-rich oligonucleotides could form G-quadruplex structures in vivo.

If G-quadruplex formation in vivo has a biological consequence, then small molecules that target and stabilize these structures could have therapeutic value. In animal chromosomes, the telomerase enzyme (which is up-regulated in certain cancers) is responsible for maintaining the telomere length thereby rendering cancer cells immortal..$^{25,26}$ The telomere is 
G-rich and has been shown via many biophysical experiments to be capable of forming G-quadruplexes. ${ }^{27-30}$ Many compounds that bind to G-quadruplexes have been shown to inhibit the extension of the DNA substrate by telomerase and some have even shown interesting anti-proliferative properties when added to cancer cells. ${ }^{31-35}$ In addition to telomeres, G-quadruplexes are present in the promoter regions of a number of cancer-related genes such as c-myc, ${ }^{36} B C L-2,{ }^{37} K R A S,{ }^{38} \mathrm{c}-k i t^{39}$ and $V E G F,{ }^{40}$ where they are involved in the regulation of transcription of these genes by disrupting binding of transcription factors. ${ }^{41,42}$

In light of these potential important biological roles of G-quadruplexes, there is high interest in discovering G-quadruplex-selective ligands for both fundamental studies (for example, fluorescent ligands that will allow for studying G-quadruplexes in vivo) and also drug-like molecules that will allow for selective targeting of G-quadruplexes related to cancer $^{17,32,43,44}$ and other diseases. ${ }^{45}$ In this manuscript, we reveal that $\mathrm{DMZ}$, which has been shown to bind to the minor groove of AT-rich DNA with a micromolar dissociation constant, binds to G-quadruplexes with a nanomolar dissociation constant, i.e. 3 orders of magnitude stronger affinity for G-quadruplexes than AT-rich duplexes. The DMZ scaffold is therefore a good starting point to develop potent G-quadruplex ligands.

\section{Material and methods}

\section{General}

4-Aminobenzamidine dihydrochloride, aniline and diminazene aceturate (DMZ or Berenil) were purchased from Aldrich. All triazenes were stored at $4{ }^{\circ} \mathrm{C}$ and in dark since significant decomposition of triazenes was observed if stored at room temperature and in presence of light. Sequences of DNA used in this study are shown in Table 1. Purified oligonucleotides 22-mer c-kit1, 18-mer VEGF, 23-mer bcl-2 2345, 15-mer TBA and 20-mer 8bp $A T$ were purchased from IDT and analyzed for purity before use. Purified WT 27-mer bcl-2, WT 24-mer c-myc, WT

Table 1 Sequences of DNA and their abbreviations used in the study

\begin{tabular}{|c|c|}
\hline Abbreviation & Sequence $\left(5^{\prime}\right.$ to $\left.3^{\prime}\right)$ \\
\hline $7 \mathrm{bp} H P^{a}$ & GCAGTCCTCTCGGACTGC \\
\hline 7bp $H P-A T^{a}$ & GCA्ATTCTCTCGAATTGC \\
\hline 8bp $A T^{a}$ & 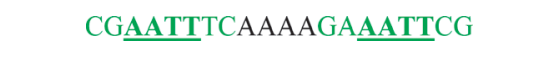 \\
\hline$T B A$ & GGTTGGTGTGGTTGG \\
\hline$V E G F$ & GGGCGGGCCGGGGGCGGG \\
\hline hTel & AGGGTTAGGGTTAGGGTTAGGG \\
\hline$c-k i t 1$ & AGGGAGGGCGCTGGGAGGAGGG \\
\hline$c-m y c$ & TGGGGAGGGTGGGGAGGGTGGGGA \\
\hline$b c l-22345$ & GGGCGCGGGAGGAATTGGGCGGG \\
\hline$b c l-2$ & CGGGCGCGGGAGGAAGGGGGCGGGAGC \\
\hline
\end{tabular}

22-mer human telomere $h \mathrm{Tel}$ were purchased from Midland Oligos (Midland, TX) and used without further purification.

DNA stock solutions were prepared by reconstituting the lyophilized oligonucleotide into $20 \mathrm{mM}$ Tris buffer with a salt concentration of $100 \mathrm{mM} \mathrm{KCl}$ and a $\mathrm{pH}$ of 7.2. Approximately $2 \mathrm{~mL}$ of the oligonucleotide was dialyzed (1000 $M_{\mathrm{w}}$ cutoff membrane) against three changes of buffer solution (1 L, $24 \mathrm{~h}$ each) at $4{ }^{\circ} \mathrm{C}$. The concentrations of stock DNA solutions were verified using UV-Vis. G-Quadruplex DNAs were annealed by quickly heating the sample to $100{ }^{\circ} \mathrm{C}$, holding at $100{ }^{\circ} \mathrm{C}$ for ten minutes then slowly cooling to $5{ }^{\circ} \mathrm{C}$, over a three hour period. Molar extinction coefficients of the DNAs were determined using a nearest-neighbor method for single stranded DNA. ${ }^{48}$ The extinction coefficients at $260 \mathrm{~nm}$ for the WT 27-mer bcl-2, WT 24-mer c-myc, WT 22-mer human telomere hTel sequences are $267200 \mathrm{M}^{-1} \mathrm{~cm}^{-1}, 248100 \mathrm{M}^{-1} \mathrm{~cm}^{-1}$, and $228500 \mathrm{M}^{-1} \mathrm{~cm}^{-1}$ respectively. ${ }^{49-51}$ The extinction coefficient at $260 \mathrm{~nm}$ for the 7 base pair hairpin with $\mathrm{A}_{2} \mathrm{~T}_{2}$ (7bp HP.AT) and the 7 base pair hairpin without $\mathrm{A}_{2} \mathrm{~T}_{2}$ (7bp HP) are $165200 \mathrm{M}^{-1} \mathrm{~cm}^{-1}$ and $159200 \mathrm{M}^{-1} \mathrm{~cm}^{-1}$ respectively. Cell culture grade water purchased from Corning was used for all experiments.

\section{Synthesis of Triazene-1 and Triazene-2}

Triazene-1. To a cooled $\left(0{ }^{\circ} \mathrm{C}\right)$ and stirred suspension of 4-aminobenzamidine dihydrochloride $(1.0 \mathrm{~g}, 4.80 \mathrm{mmol})$ in water $(6 \mathrm{~mL})$ and concentrated hydrochloric acid $(1 \mathrm{~mL})$, a solution of sodium nitrite $(0.36 \mathrm{~g}, 5.28 \mathrm{mmol})$ in water $(1 \mathrm{~mL})$ was added dropwise and the mixture was stirred for $20 \mathrm{~min}$ utes. To the resulting diazonium solution, a solution of aniline $(0.43 \mathrm{~mL}, 4.80 \mathrm{mmol})$ in $\mathrm{MeOH}(1 \mathrm{~mL})$ was added followed by addition of saturated aqueous sodium acetate $(6 \mathrm{~mL})$. After being stirred at $0{ }^{\circ} \mathrm{C}$ for $1 \mathrm{~h}$, the resultant yellow solid was filtered off, washed with brine, dried and crystallized with $\mathrm{MeOH} /$ acetone $(1: 2,20 \mathrm{~mL})$ to afford analytically pure product $(1.2 \mathrm{~g}, 84 \%)$ as an acetate salt. ${ }^{1} \mathrm{H}$ NMR $\left(\mathrm{DMSO}_{6}, 400 \mathrm{MHz}\right)$ $\delta$ 7.87-7.83 (m, 2H), 7.57-7.47 (m, 4H), 7.47-7.42 (m, 2H), 7.31$7.26(\mathrm{~m}, 1 \mathrm{H}), 1.72(\mathrm{~s}, 3 \mathrm{H}) .{ }^{13} \mathrm{C}$ NMR (DMSO-d $6,100 \mathrm{MHz}$ ) $\delta 177.1,165.8,148.9,148.4,130.2,130.1,127.4,123.4,120.5$, 116.1, 25.8. HRMS $\left(\mathrm{ESI}^{+}\right) \mathrm{m} / z$ calcd. for $\mathrm{C}_{13} \mathrm{H}_{14} \mathrm{~N}_{5}[\mathrm{M}+\mathrm{H}]^{+}$ 240.1249, found 240.1248 .

Triazene-2. Following the procedure described above for the Triazene-1, diazonium solution of aniline $(0.5 \mathrm{~mL}, 5.47 \mathrm{mmol})$ was treated with aniline $(0.5 \mathrm{~mL}, 5.47 \mathrm{mmol})$ to afford Triazene$2(1.1 \mathrm{~g}, 85 \%)$, as a yellow solid. ${ }^{1} \mathrm{H}$ NMR $\left(\mathrm{CDCl}_{3}, 400 \mathrm{MHz}\right)$ $\delta$ 7.47-7.39 (m, 8H), $7.20(\mathrm{tt}, J=6.9,1.5 \mathrm{~Hz}, 2 \mathrm{H}) .{ }^{13} \mathrm{C}$ NMR (DMSO-d 6 , $100 \mathrm{MHz}$ ) $\delta 150.7,142.6,130.1,127.7,123.1,121.6$, 114.9. HRMS (ESI $\left.{ }^{+}\right) \mathrm{m} / z$ calcd. for $\mathrm{C}_{12} \mathrm{H}_{12} \mathrm{~N}_{3}[\mathrm{M}+\mathrm{H}]^{+}$198.1031, found 198.1031.

NMR spectra for synthesized compounds were recorded with a Bruker AV-400 or Bruker DRX-400. ${ }^{1} \mathrm{H}-\mathrm{NMR}$ chemical shifts are reported as $(\delta)$ in ppm and are calibrated according to residual solvent peaks. ${ }^{1} \mathrm{H}$ NMR coupling constants ( $J$ values) are reported in Hertz $(\mathrm{Hz}) .{ }^{13} \mathrm{C}-\mathrm{NMR}$ chemical shifts are reported as ppm relative to residual solvent peak. Highresolution mass spectra (HRMS) for synthesized compounds 
were recorded with JEOL AccuTOF-CS (ESI positive, needle voltage 1800-2400 eV).

\section{UV titration studies of DNA with the triazene ligands, DMZ and Triazene-1}

UV measurements for titration studies were done using a JASCO V-630 spectrophotometer. Fluorescence measurements for the displacement assay were done using a Varian Cary Eclipse fluorimeter. The molar extinction coefficients at $260 \mathrm{~nm}$ for 22-mer c-kit1, 18-mer VEGF, 23-mer bcl-2 2345, 15-mer TBA and 20-mer 8bp $A T$ are as follows $226700 \mathrm{M}^{-1} \mathrm{~cm}^{-1}, 169800 \mathrm{M}^{-1} \mathrm{~cm}^{-1}$, $227300 \mathrm{M}^{-1} \mathrm{~cm}^{-1}, 143300 \mathrm{M}^{-1} \mathrm{~cm}^{-1}$ and $205500 \mathrm{M}^{-1} \mathrm{~cm}^{-1}$, respectively. The concentration of ligands used in this study was $10 \mu \mathrm{M}$ and the DNA concentrations were $0,0.25,1.5,3,5,6,7,8,9$, $10,20,30,40,50,100$, and $150 \mu \mathrm{M}$. The buffer contained $250 \mathrm{mM}$ $\mathrm{KCl}, 50 \mathrm{mM}$ Tris-HCl (at $\mathrm{pH}$ 7.5). The following quadruplex DNA were tested: c-kit1, VEGF, bcl-2 2345, and TBA. Duplex DNA (8bp $A T$ ) was also tested. The sample was first heated up to $95{ }^{\circ} \mathrm{C}$ for $5 \mathrm{~min}$ without the ligand and then cooled down to room temperature in $15 \mathrm{~min}$. The ligand was then added and the mixture was incubated at $4{ }^{\circ} \mathrm{C}$ for $\sim 12 \mathrm{~h}$ before recording the data. In case of Triazene- 1 and Triazene-2, the sample mixture contained 1\% DMSO.

\section{NMR measurements for DNA binding of triazene ligands}

NMR measurements for the binding studies were done using Bruker Avance III HD 800 spectrometer equipped with CryoProbe. The procedures used in the binding studies were described previously. ${ }^{46}$ The ligand concentration was $150 \mu \mathrm{M}$, and that of the DNA (c-kit1 or $8 \mathrm{bp} A T$ ) was $300 \mu \mathrm{M}$. The buffer used was $10 \mathrm{mM}$ potassium phosphate ( $\mathrm{pH}$ 7.5) containing $137 \mathrm{mM} \mathrm{NaCl}, 1 \mathrm{mM}$ EDTA, and also contained $10 \% \mathrm{D}_{2} \mathrm{O}$. The sample was initially heated up to $95{ }^{\circ} \mathrm{C}$ for $5 \mathrm{~min}$ without the ligand and then cooled down to room temperature in $15 \mathrm{~min}$. Subsequently, the sample was incubated at $4{ }^{\circ} \mathrm{C}$ for $\sim 12 \mathrm{~h}$ without the ligand (for G-quadruplex formation). Then, the ligand was added and incubated for $2 \mathrm{~h}$ before the NMR measurement $\left(25^{\circ} \mathrm{C}\right)$. (Note: because of the high concentrations being used for the NMR, incubating the DNA/ligand for longer periods caused precipitation, probably due to G-quadruplex polymer formation, which is catalyzed by the ligand).

\section{Isothermal titration calorimetry}

ITC experiments were performed using a VP-ITC calorimeter (GE-Heathcare). A typical ITC experiment involved the addition of $28(10 \mu \mathrm{L})$ injections of a nominal $1 \mathrm{mM}$ ligand solution into $\sim 1.5 \mathrm{~mL}$ of a dilute DNA solution $(10 \mu \mathrm{M})$. All ITC titration experiments were done at $25{ }^{\circ} \mathrm{C}$. Corrected titration curves were obtained by subtracting the blank titration data from the ITC-data for the ligand-DNA titrations. The corrected ITC titrations were fit to a multiple independent sites binding model using a nonlinear regression algorithm, CHASM, developed in our laboratory. ${ }^{47}$

\section{Circular dichroism (CD)}

CD titration experiments were performed with an Olis DSM-20 spectropolarimeter (Bogart, GA). All measurements were done at $25{ }^{\circ} \mathrm{C}$ using a $1 \mathrm{~cm}$ quartz cuvette and covering a spectral range of 220-420 $\mathrm{nm}$. All DNA samples were prepared such that they had a nominal absorbance of less than 1.0 at $260 \mathrm{~nm}$. Stock solutions of the ligand were added in small amount to reach a molar ratio of $1: 1,3: 1,6: 1$, and $10: 1$ of ligand per equivalence of DNA.

\section{Electrospray ionization mass spectrometry}

ESI-MS experiments on the triazene-DNA complexes were carried out on a Bruker MicrOTOFQ mass spectrometer. Data acquisition was set to operate in negative ion mode. All experiments were performed in $50 \mathrm{mM}$ ammonium acetate buffer containing 20\% HPLC grade methanol and adjusted with $1 \mathrm{~N}$ $\mathrm{KOH}$ solution to reach $\mathrm{pH}$ of 7.0. The WT hTel 22-mer G-quadruplex sample was prepared at a concentration of approximately $10 \mu \mathrm{M}$ in the ammonium acetate buffer and was exhaustedly dialyzed. Stock solutions of DMZ and Triazene1 were prepared in the final dialysate buffer at concentration as high as $300 \mu \mathrm{M}$. The ESI-MS samples were prepared by mixing the DNA and ligand stock solutions to yield a mixture containing excess of each ligand per equivalence of DNA. The MS capillary voltage was set to $+3500 \mathrm{~V}$, dry $\mathrm{N}_{2}$ gas flow was adjusted to $0.5 \mathrm{~L} \mathrm{~min}^{-1}$ at $110{ }^{\circ} \mathrm{C}$, and the G-quadruplex/ligand samples were directly infused into the $\mathrm{MS}$ by using a $\mathrm{kD}$ Scientific syringe pump set to a flow rate of $200 \mu \mathrm{L}$ per hour. Data processing was performed by using the Bruker Daltonics Data Analysis program.

\section{Results and discussion}

Recently, there has been considerable interest in repurposing drugs for new therapeutic indications. ${ }^{52,53}$ Along this line, others have been interested in repurposing DNA duplex minor groove binders for targeting G-quadruplexes. ${ }^{54-57}$ Compounds that bind minor grooves of DNA duplexes have a track record of clinical efficacy for many indications including animal trypanosomiasis and babesiosis. ${ }^{58}$ Because there are numerous toxicological data for these drugs, using them as starting points for the development of G-quadruplex-selective ligands appears to be a reasonable proposition. Curiously, although several duplex minor groove binders have been tested for G-quadruplex binding, DMZ (Fig. 1) a prototypical AT-rich minor groove binder, which is used clinically to treat animal trypanosomiasis has not been thoroughly investigated for G-quadruplex binding. To date there is only a single report, from our laboratory, that demonstrated that DMZ aggregates the dinucleotide, c-di-GMP, into an ill-defined supramolecular aggregate (probably containing G-quadruplexes) via an uncharacterized mechanism. $^{59}$

\section{DMZ as a G quadruplex ligand}

UV spectroscopy studies of DMZ binding to G quadruplexes and duplex DNA. We initiated our study by testing if DMZ or analogs could compete with a known G-quadruplex ligand, such as the fluorogenic $N$-methyl mesoporphyrin IX (NMM), in binding to $c$-kit1 (see Fig. S1, ESI $\dagger$ ). Having obtained 


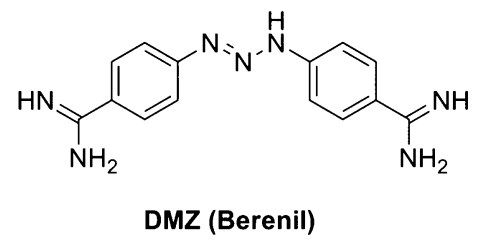

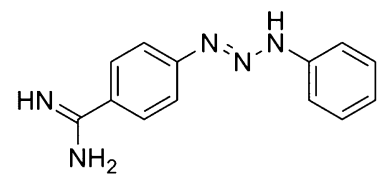

Triazene-1

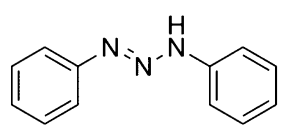

Triazene-2

Fig. 1 Structures of DMZ, Triazene-1, and Triazene-2.

preliminary results that DMZ could indeed compete with NMM for $c$-kit1 binding, we proceeded to perform a series of experiments to confirm whether the binding of DMZ to DNA G-quadruplexes was real. This started with studies of the interaction of DMZ with various G-quadruplex DNAs (c-kit1, $V E G F, b c l-22345$ and TBA; see Table 1 for their sequences) using a conventional UV-visible absorption titration method employing an AT-rich duplex DNA, 8bp AT, as positive control. The absorption spectra of DMZ $(10 \mu \mathrm{M})$ with different concentrations of G-quadruplex DNA $(0-150 \mu \mathrm{M})$ are shown in Fig. 2 and Fig. S2 (ESI $\dagger$ ). Interestingly, gradually increasing the DNA concentration, resulted in a significant bathochromic shift (red shift) and a hypochromic effect on the $360 \mathrm{~nm}$ DMZ band for all of the tested G-quadruplexes (Fig. 2 and Fig. S2, ESI $\dagger$ ). These observed effects in the UV-absorption spectra provided direct evidence for a strong interaction between DMZ and the G-quadruplex targets.

Importance of amidine moiety in DMZ binding to duplex DNA and G-quadruplexes. Analysis of the crystal structure of DMZ/duplex DNA ${ }^{60}$ complex (Fig. 3) revealed that both amidine groups in DMZ make important and extensive contacts with the minor groove residues. Therefore we reasoned that the modification of one or both of the amidine groups could give an analog that would be incapable of binding to DNA minor groove. However it was unclear if the deletion of the amidine group would also reduce binding to G-quadruplexes.

We synthesized two DMZ analogs (Triazene-1, which has one of the amidine groups in DMZ deleted and Triazene- $2,{ }^{61}$ which does not contain any amidine group, see Fig. 3). These DMZ analogs were then evaluated on the basis of their affinity for binding to both duplex and G-quadruplex DNA. The synthesis of Triazene- 1 and Triazene-2, following precedent, ${ }^{61}$ is outlined
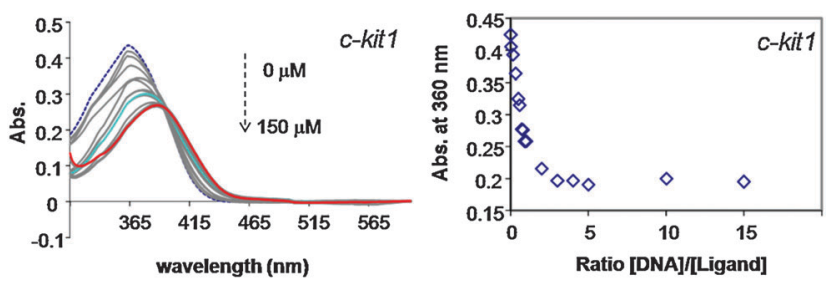

Fig. 2 UV-titration studies showing binding of DMZ with DNA. (left) Absorption spectra of DMZ $(10 \mu \mathrm{M})$ upon titration with c-kit1. The concentrations of DNA are $0,0.25,1.5,3,5,6,7,8,9,10,20,30,40,50,100,150 \mu \mathrm{M}$. In the graph, $10 \mu \mathrm{M}$ and $150 \mu \mathrm{M}$ DNA concentrations are specifically emphasized as cyan and red line respectively. $[\mathrm{KCl}]=250 \mathrm{mM}$, Buffer $=$ $50 \mathrm{mM}$ Tris- $\mathrm{HCl}(\mathrm{pH} 7.5)$. UV was measured at $20{ }^{\circ} \mathrm{C}$. (right) Plot of absorbance at $360 \mathrm{~nm}$ against concentration ratio of DNA and ligand (DMZ). in Scheme 1. First, the diazonium salts of $p$-aminobenzamidine and aniline were generated by treating with sodium nitrite followed by their coupling with aniline to give Triazene- 1 and Triazene-2 in good yields. Both of the synthesized triazenes were characterized by mass and NMR spectroscopy (see ESI $\dagger$ for spectral data).

\section{UV spectroscopy studies of Triazene-1 binding to G quadruplexes and duplex DNA}

In qualitative UV-visible titration experiments, the absorbance maxima of Triazene-1 $(10 \mu \mathrm{M})$ displayed a red shift with increasing concentrations of various G-quadruplexes (Fig. 4 and Fig. S3, ESI $\dagger$ ), implying binding while Triazene-2, exhibited selfaggregation (data not shown here) and was not considered further. In contrast, when Triazene-1 was incubated with duplex DNA (Fig. S3E, ESI $\dagger$ ), there was no evidence for a robust interactions between the Triazene- 1 and an AT rich duplex DNA. Visual inspection of the UV titration experiments (compare Fig. 2, Fig. S2 (ESI $\dagger$ ) and Fig. 4, Fig. S3, ESI $\dagger$ ) revealed that DMZ had a higher affinity to the G-quadruplexes than Triazene-1, the DMZ analog having only one amidine group. The differences in affinity (selectivity) between DMZ and Triazene- 1 for binding to duplex AT minor groove sites vs. G-quadruplex stacking or intercalation interactions were quantified using ITC experiments, vide infra.

\section{NMR analysis of binding of DMZ and Triazene-1 to DNA}

To provide direct evidence for the binding of DMZ and Triazene-1 to $c$-kit1 (G-quadruplex) and duplex DNA, we performed ${ }^{1} \mathrm{H}$-NMR titration experiments. Xu and co-workers used NMR to investigate the binding of a cyanine dye to $c$-kit 1 so we decided to start with $c$-kit1, based on this precedent. ${ }^{18,46}$ In general, the guanine imino protons resonate between 10.0 to $12.5 \mathrm{ppm}$ in a quadruplex matrix and this represents guanine $\mathrm{NH} \cdots \mathrm{O}$ hydrogen bonds in the Hoogsteen alignments of G-quartets. Upon binding of small molecules, the chemical environment around these imino protons changes, resulting in changes in their NMR chemical shifts. Fig. 5A shows the NMR spectra of the guanine imino protons of c-kit 1 in presence of the ligands, DMZ and Triazene- 1 in $90 \% \mathrm{H}_{2} \mathrm{O} / \mathrm{D}_{2} \mathrm{O}$. The chemical shifts for the guanine imino protons in the spectrum of $c$-kit1 alone (Fig. 5A), ([ligand] : [c-kit1] $=0: 1$ ) was assigned based on the earlier work. ${ }^{46}$ The NMR titration spectra of DMZ and Triazene-1 with $c$-kit1 show significant decreases in the peak intensities and line-broadening in the imino proton spectra (Fig. 5A). These results demonstrate direct binding of DMZ and Triazene-1 to c-kit1 (NMR resonances between 11.1 and 


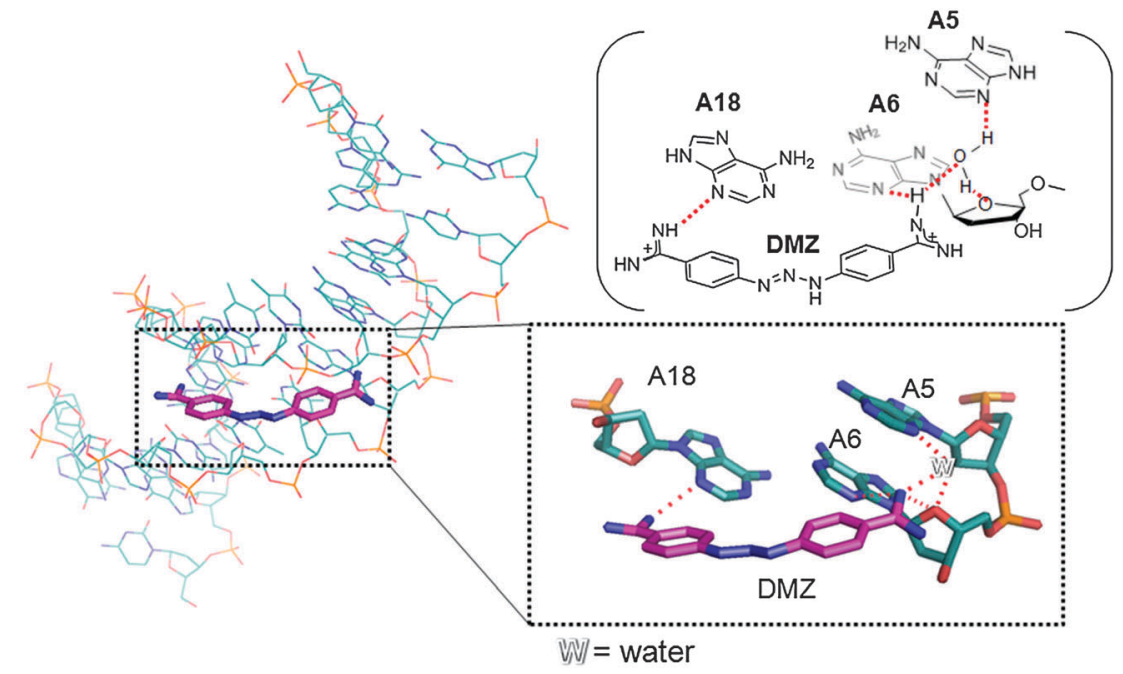

Fig. 3 DMZ interactions with duplex DNA (AT-rich). The amidine groups of DMZ make important hydrogen-bonding interactions with both DNA residues and water molecules in the minor groove of DNA (structure is from PDB\#2DBE).<smiles>[R]c1ccc(N)cc1</smiles>

(i) $\mathrm{NaNO}_{2}$, conc. $\mathrm{HCl}$, $\mathrm{H}_{2} \mathrm{O}, 0^{\circ} \mathrm{C}, 20 \mathrm{~min}$

(ii) Aniline, $\mathrm{CH}_{3} \mathrm{CO}_{2} \mathrm{Na}$, $0{ }^{\circ} \mathrm{C}, 1 \mathrm{hr}$

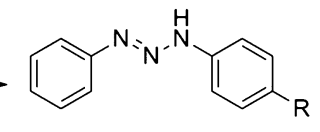

Triazene 1, $\mathrm{R}=-\xi \mathrm{NH}_{\mathrm{NH}}^{\mathrm{NH}}$ $(84 \%)$

Triazene 2, $\mathrm{R}=\mathrm{H}(85 \%)$

Scheme 1 Synthesis of triazene ligands.
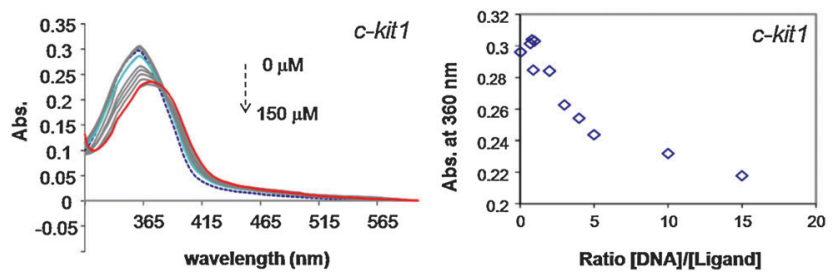

Fig. 4 UV-titration studies of binding of Triazine-1 with DNA. (left) Absorption spectra of Triazene-1 $(10 \mu \mathrm{M})$ upon titration with c-kit1. The concentrations of DNA are $0,0.25,1.5,3,5,6,7,8,9,10,20,30,40,50,100,150 \mu \mathrm{M}$. In the graph, $10 \mu \mathrm{M}$ and $150 \mu \mathrm{M}$ DNA concentration is specifically emphasized as cyan and red line. $[\mathrm{KCl}]=250 \mathrm{mM}$, Buffer $=50 \mathrm{mM}$ Tris- $\mathrm{HCl}(\mathrm{pH} 7.5)$. UV was measured at $20{ }^{\circ} \mathrm{C}$. (right) Plot of absorbance at $360 \mathrm{~nm}$ against concentration ratio of DNA and ligand (Triazene-1).

11.4 $\mathrm{ppm}$ are different between the case with no ligand added and when DMZ or triazene are added), consistent with our UV-visible titration experiments (Fig. 2, Fig. S2 (ESI $\dagger$ ) and Fig. 4, Fig. S3, ESI $\dagger$ ). When DMZ or Triazene- 1 was added to $c$-kit1, the chemical shifts associated with the imino protons of G6, G10 and G2 did not change, probably excluding end-stacking with the $5^{\prime}$-terminal tetrad of the quadruplex. Other NMR titration experiments with other G-quadruplexes, such as $V E G F$ and $b c l-2$ 2345 did not give stable baselines (data not shown), probably due to aggregation of the ligand-DNA complex. Despite this technical difficulty, the $c$-kit1 NMR titration data provide good evidence that DMZ does indeed bind to G-quadruplex DNA.
To further explore the interaction of the DMZ and Triazene-1 ligands with duplex DNA, NMR experiments in which $8 \mathrm{bp}-A T$ was incubated with the triazene ligands were performed as described for $c$-kit1 above. In the case of duplex DNA (8bp AT), only DMZ (but not Triazene-1) showed significant changes in the imino region of spectrum of the duplex DNA (see Fig. 5B). This is consistent with the UV titration data, which showed that Triazene-1 did not bind to AT-rich duplex DNA (see Fig. 4 and Fig. S3, ESI†).

NMR titration experiments have demonstrated that both DMZ and Triazene-1 bind to the $c$-kit1 G-quadruplex. However, a definitive identification of the DMZ and Triazene-1 binding sites was not possible with the current NMR data (Fig. 5A). Future work will be focused on obtaining structural information for G-quadruplex DNA/DMZ (and/or DMZ analog) complexes via X-ray crystallography and/or NMR. Such studies would provide important information that will be used to design next generation triazene analogs that could have higher affinity and selectivity for G-quadruplex DNA.

Initial screening experiments employing UV and NMR titration methods, provided qualitative evidence that DMZ binds to both duplex and G-quadruplex DNA whereas Triazene-1 binds only to G-quadruplex DNA (and not AT rich duplex DNA) albeit with lower affinity than DMZ. However, neither the UV nor NMR methods are sensitive enough for the accurate determination of sub-micromolar binding constants. By employing ITC, we were able to determine the energetics for the interactions of DMZ and Triazene- 1 with several commonly studied G-quadruplex constructs $h T e l, c-m y c, b c l-2$. We also used ITC to study the interactions between DMZ and Triazene-1 and two hairpin duplex DNA constructs, one having an $\mathrm{A}_{2} \mathrm{~T}_{2}$ binding site, 7bp HP-AT, and one without the $\mathrm{A}_{2} \mathrm{~T}_{2}$ site, 7bp HP. The sequences for these DNA targets were shown in Table 1.

\section{DMZ-Triazene-1-hTel22 complexes identified via mass spectroscopy}

We have previously reported on the thermodynamic properties for the binding of several porphyrins and porphyrin derivatives 
(A)

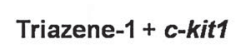

Triazene-1 + c-kit1

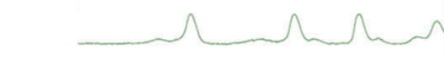

$\mathrm{DMZ}+$ c-kit1

c-kit1 alone

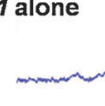

(B)

Triazene-1 + 8bp AT

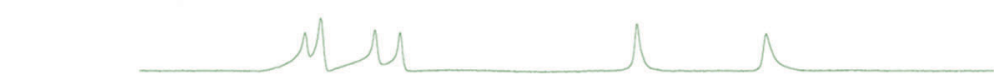

$\mathrm{DMZ}+8 \mathrm{bp} A T$
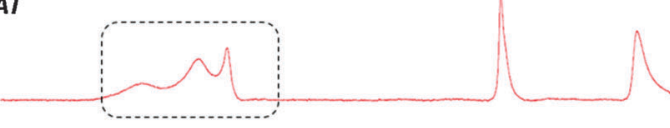

8bp AT alone
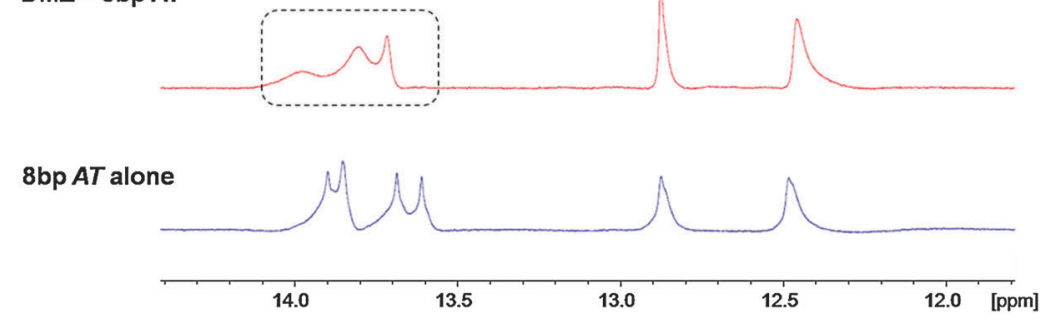

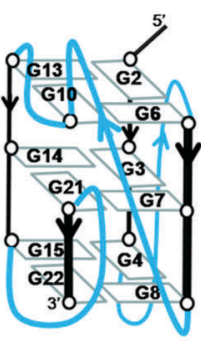

[ppm]

Fig. $5{ }^{1} \mathrm{H}$-NMR spectra of DNA incubated with ligands. [DMZ] or [Triazene-1] $=150 \mu \mathrm{M},[\mathrm{DNA}]=300 \mu \mathrm{M}(\mathrm{ratio}$ ligand: DNA $=0.5: 1), \mathrm{D}_{2} \mathrm{O}=10 \%$, Buffer $=10 \mathrm{mM} \mathrm{K}$-phosphate buffer $(\mathrm{pH} 7.5),[\mathrm{NaCl}]=137 \mathrm{mM}$, [EDTA] $=1 \mathrm{mM}$. The ligand was incubated with DNA for $2 \mathrm{~h}$ at $4{ }^{\circ} \mathrm{C}$ before measurement. (A) DNA = c-kit1. (B) DNA $=8 \mathrm{bp} A T$.

to a variety of oncogene promoter sequence G-quadruplexes. ${ }^{62,63}$ We have repeatedly shown that the cationic porphyrin TMPyP4 binds to a number of G-quadruplexes and forms complexes having a saturation stoichiometry of $(n+1)$ where $\mathrm{n}$ is the number of G-tetrads in the G-quadruplex motif. In the case of the $c-m y c, b c l-2$, and kras promoter sequence G-quadruplexes the saturation stoichiometry was determined to be 4 moles of TMPyP4 per mole of G4-DNA. ${ }^{62,63}$ The DMZ (or Triazene-1) ligands are approximately half the size of TMPyP4 and we would speculate that two molecules of DMZ (or Triazene-1) could pi-stack with one G-tetrad (see Fig. 6). The ESI mass spectra for a solution containing hTel22 DNA in an excess amount of DMZ (panel A) and/or an excess amount of Triazene-1 (panel B) indicate that up to 8 molecules of these ligands can bind to one G-quadruplex. Three important features can be observed from panel A: first, there are no observable $\mathrm{m} / \mathrm{z}$ peaks for free DNA; second, there are multiple $\mathrm{m} / \mathrm{z}$ peaks indicating stoichiometry

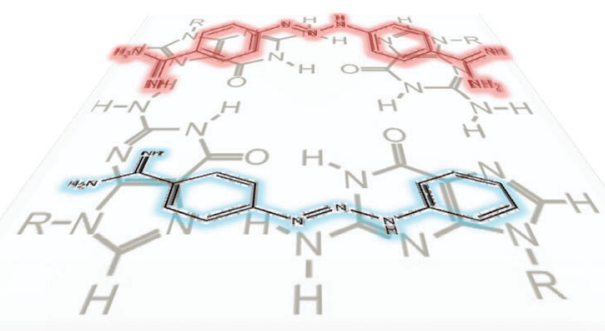

Fig. 6 Chemical structures of Diminazene aceturate (DMZ) and Triazene-1 in comparison to a chemical representation of a G-quartet. values larger than $4: 1$; and third, DMZ.hTel22 complexes are observed with stoichiometries up to $8: 1$ as evidenced from the $\mathrm{m} / \mathrm{z}$ peaks at 1843.3 and 2314.0. Similarly, the ESI mass spectrum shown in Fig. 7 panel B for a solution containing hTel22 in an excess amount of Triazene-1 also suggests a maximum stoichiometry of $8: 1$. However, there are notable differences between the data shown in panels A and B. The mass spectrum shown in panel B clearly exhibits the presence of some free or uncomplexed DNA as evidenced by $\mathrm{m} / \mathrm{z}$ peaks at 1751.5 and 2328 . The presence of free DNA even in excess amounts of Triazene- 1 ligand suggests a low binding affinity for the interaction of Triazene-1 with the hTel22 G-quadruplex DNA.

\section{Determination of DMZ and Triazene-1 binding constants to DNA using ITC}

Typical raw ITC data for the titration of DMZ into five different DNA samples, 7bp HP.AT, $7 \mathrm{bp} H P, 27$ mer $b c l-2,24$ mer $c-m y c$, and 22mer $h T e l$, are shown in Fig. S4 (ESI $\dagger$ ). The thermodynamic parameters for the interaction of DMZ with these DNAs were obtained directly from the nonlinear regression fits of the raw ITC data to a one site, fractional one site, or three competitive sites thermodynamic binding model, depending on the number of species indicated in the thermograms. As shown in Fig. S4 (ESI $\dagger$ ), the binding of DMZ to 7bp HP.AT exhibits two different but independent overlapping binding modes and is reminiscent of the binding of netropsin (another AT minor groove binder). ${ }^{64-67}$ The interaction of DMZ with the 7bp HP sequence, lacking the $\mathrm{A}_{2} \mathrm{~T}_{2}$ site, exhibits weaker complex formation (and only one binding mode). The interactions between DMZ and 27mer $b c l-2$ 

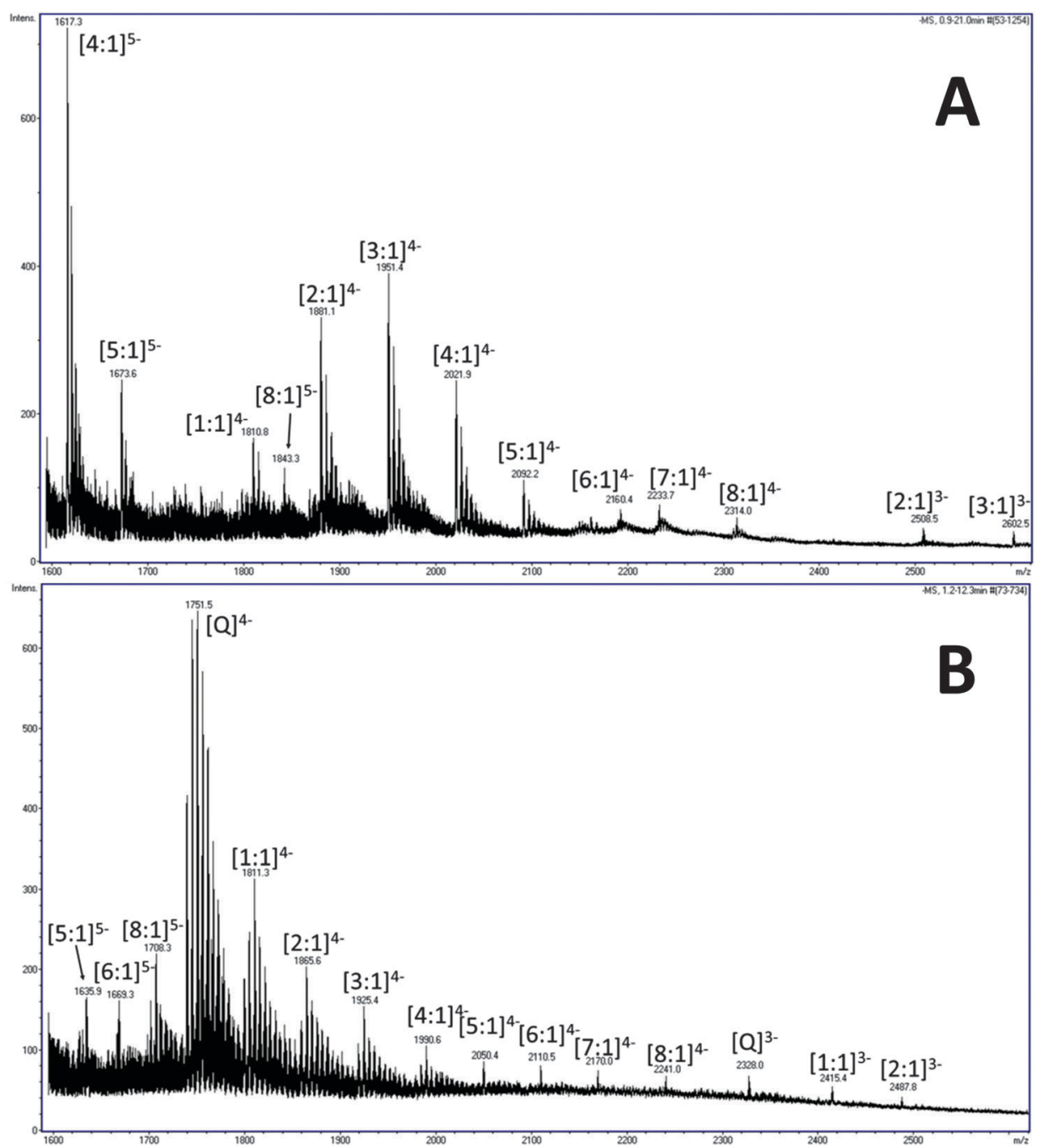

Fig. 7 ESI mass spectrum for $h$ Tel22 solution containing excess amount of DMZ (panel A) and ESI mass spectrum for hTel22 solution containing excess amount of Triazene-1 (panel B). $Y$-axis is relative intensity and $x$-axis is $\mathrm{m} / \mathrm{z}$.

or 24 mer $c-m y c$ are best described by at least three different binding processes. Typical nonlinear regression fits for the analysis of the binding of DMZ to 7bp HP, 7bp HP-AT and $b c l-2$, and c-myc are shown in Fig. 8. The solid lines in Fig. 8 represent the model lines using the best fit thermodynamic parameters for these ligand DNA interactions.

The thermodynamic parameters obtained from the ITC experiments (Fig. S4, ESI $\dagger$ and fits Fig. 8) reveal that DMZ binds to some G-quadruplex DNAs (for example $b c l-2$ and $c$-myc) with dissociation constants as low as $\sim 1 \mathrm{nM}$. This is of a similar affinity to that exhibited by guanidine phthalocyanines, considered to be one of the tightest binders of G-quadruplexes with $K_{\mathrm{d}}$ of $\sim 2 \mathrm{nM} .{ }^{17}$ Also the ligand TMPyP4, a classic G-tetrad binding ligand, binds to G-quadruplexes with $K_{\mathrm{d}} \approx 2 \times 10^{-7} \mathrm{M},{ }^{62,68}$ so the fact that DMZ binds to G-quadruplexes with $1 \mathrm{nM}$ dissociation constant is interesting. Of note is the observation that even the second dissociation constant, $K_{\mathrm{d} 2} \approx 5 \times 10^{-8} \mathrm{M}$, for the DMZ.c-myc complex is an order of magnitude smaller than the dissociation constant $\left(K_{\mathrm{d}} \approx 1 \times 10^{-6} \mathrm{M}\right)$ obtained for the DMZ. 7bp HP-AT complex. Our $K_{\mathrm{d}}$ value for the DMZ-7bp HP-AT complex is very similar to the dissociation constant $\left(K_{\mathrm{d}} \approx 1 \times\right.$ $10^{-6} \mathrm{M}$ ) determined in NMR experiments previously reported by Jenkins et al. for DMZ interactions with several types of B-DNAs containing the AT rich sequences. ${ }^{69}$ Interestingly, Jenkins et al. also mentioned the two overlapping events exhibited by the interactions of DMZ with AT rich sequences. ${ }^{69}$ The phenomenon of two overlapping sites observed for the AT rich sequence has been well documented and several possible mechanisms have been suggested, including: (1) two binding orientations of the minor groove binder in the DNA minor groove or (2) the formation of a complex in which one or more water molecules are trapped between the ligand binding in the minor groove and the floor of the DNA groove. ${ }^{64-66}$

The ITC heat data for the titrations of Triazene- 1 to four different DNA sequences (a DNA hairpin and three G-quadruplex DNAs) are shown in Fig. S5 (ESI $\dagger$ ). Again, from visual inspection, it seems that the titration of Triazene- 1 into $\mathrm{Na}^{+} h$ Tel22 is calorimetrically silent while the addition of Triazene- 1 to $\mathrm{K}^{+}$ 

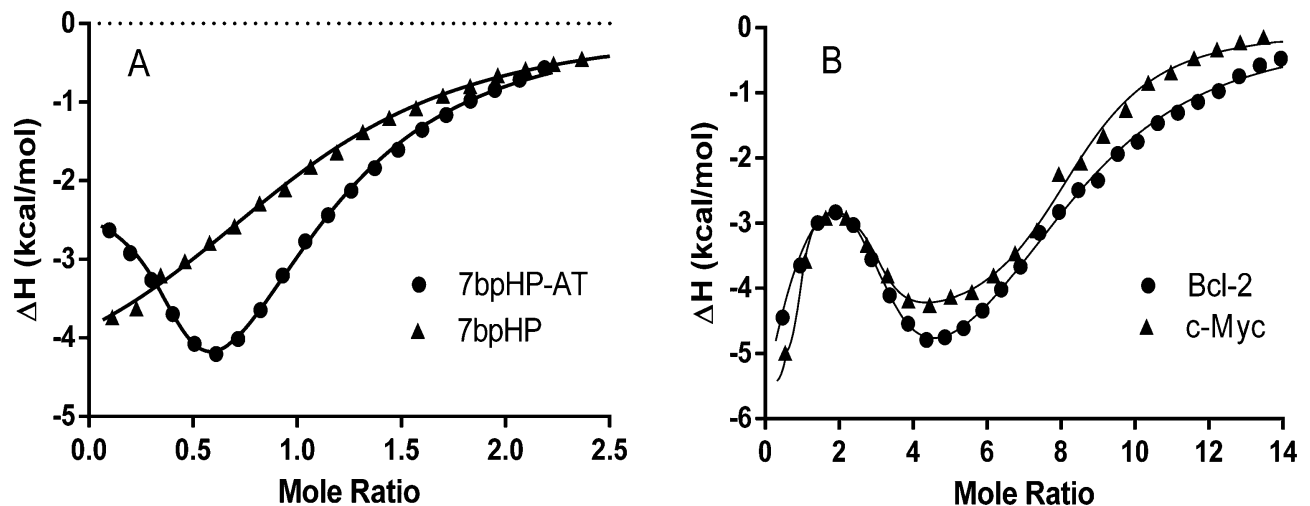

Fig. 8 Typical nonlinear regression fits for the DMZ titrations of 7bp HP, and 7bp HP.AT are shown in panel A. The 7bp HP titration data are fit to a one site model and the $7 \mathrm{bp} \mathrm{HP.AT} \mathrm{data} \mathrm{are} \mathrm{fit} \mathrm{to} \mathrm{a} \mathrm{fractional} \mathrm{two} \mathrm{site} \mathrm{model.} \mathrm{Typical} \mathrm{nonlinear} \mathrm{regression} \mathrm{fits} \mathrm{for} \mathrm{the} \mathrm{DMZ} \mathrm{titrations} \mathrm{of} 27 \mathrm{mer} b c \mathrm{-}-2$ and $24 \mathrm{mer}$ $c$-myc are shown in panel B. Both the $27 \mathrm{mer} b c \mathrm{-}-2$ and the $24 \mathrm{mer} c-m y c$ DMZ titration data are fit to a three site model. The best fit parameters for the data shown in panels $A$ and $B$ are listed in Table 2 .

hTel22 results in a significant exothermic signal. Notable differences between the DMZ and the Triazene-1 DNA titration experiments are that DMZ exhibits a much tighter binding affinity than Triazene-1, at least for the preferred G-quadruplexes, and Triazene-1 exhibits only a single binding event for its interactions with the $b c l-2$, and $c-m y c$ G-quadruplexes. In addition, the binding affinity for Triazene-1 interacting with $\mathrm{K}^{+} h \mathrm{Tel22}$ is similar to the binding affinities for Triazene-1 interacting with either the $b c l-2$ or c-myc G-quadruplexes. This result is in sharp contrast to DMZ which exhibits selectivity for the $b c l-2$ or $c-m y c$ G-quadruplexes over $\mathrm{K}^{+} h$ Tel22. Triazene-1 binds to all of the tested G-quadruplexes with significantly lower affinity (4-5 orders of magnitude lower, compare Tables 2 and 3) than does DMZ. The binding affinity for of Triazene- 1 with $7 \mathrm{bp} H P-A T$ is also reduced by a

Table 2 Thermodynamic data obtained from ITC experiments for the formation of the DMZ complexes with several different DNAs

\begin{tabular}{|c|c|c|c|c|c|c|}
\hline Sequences & $\begin{array}{l}K_{1} \\
\left(\mathrm{M}^{-1}\right)\end{array}$ & $\begin{array}{l}\Delta H_{1} \\
(\mathrm{kcal} \\
\left.\mathrm{mol}^{-1}\right)\end{array}$ & $\begin{array}{l}K_{2} \\
\left(\mathrm{M}^{-1}\right)\end{array}$ & $\begin{array}{l}\Delta H_{2} \\
\left(\mathrm{kcal}^{-1}\right) \\
\left.\mathrm{mol}^{-1}\right)\end{array}$ & $\begin{array}{l}K_{3} \\
\left(\mathrm{M}^{-1}\right)\end{array}$ & $\begin{array}{l}\Delta H_{3} \\
\left(\mathrm{kcal}^{-1}\right) \\
\left.\mathrm{mol}^{-1}\right)\end{array}$ \\
\hline $7 \mathrm{bp} H P \cdot A$ & $9.8 \times 10^{5}$ & -2.2 & $4.5 \times 10^{4}$ & -8.7 & - & - \\
\hline $7 \mathrm{bp} H P$ & - & - & $1.8 \times 10^{4}$ & -5.3 & - & - \\
\hline $27 \mathrm{mer} b c l-2$ & $8.8 \times 10^{8}$ & -4.5 & $1.9 \times 10^{6}$ & -2.2 & $6.4 \times 10^{4}$ & -7.3 \\
\hline 24 mer $c-m y c$ & $7.6 \times 10^{8}$ & -5.5 & $1.9 \times 10^{7}$ & -2.5 & $2.8 \times 10^{5}$ & -4.7 \\
\hline $22 \mathrm{mer} h \mathrm{Tel} \mathrm{Na}^{+}$ & $\mathrm{Nd}$ & $\mathrm{Nd}$ & $\mathrm{Nd}$ & $\mathrm{Nd}$ & $\mathrm{Nd}$ & $\mathrm{Nd}$ \\
\hline $22 \mathrm{mer} h \mathrm{Tel} \mathrm{K}^{+}$ & - & - & - & - & $5.5 \times 10^{4}$ & -3.8 \\
\hline
\end{tabular}

$\mathrm{Nd}=$ not determined. Note: $K_{1}, K_{2}$ and $K_{3}$ are association constants. Dissociation constants, $K_{\mathrm{d}}=1 /\left(K_{1}\right.$ or $K_{2}$ or $\left.K_{3}\right)$.

Table 3 Thermodynamic data obtained from ITC experiments for the formation of the Triazene-1 complexes with several different DNAs

\begin{tabular}{lll}
\hline Sequences & $K_{1}\left(\mathrm{M}^{-1}\right)$ & $\Delta H_{1}\left(\mathrm{kcal} \mathrm{mol}^{-1}\right)$ \\
\hline 7bp HP-AT & $2.9 \times 10^{4}$ & -1.9 \\
7bp HP & $\mathrm{Nd}$ & $\mathrm{Nd}$ \\
$27 \mathrm{mer} b c l-2$ & $3.5 \times 10^{3}$ & -1.8 \\
24 mer $c-m y c$ & $3.6 \times 10^{4}$ & -1.1 \\
$22 \mathrm{mer} h \mathrm{hel} \mathrm{Na}$ & $\mathrm{Nd}$ & $\mathrm{Nd}$ \\
$22 \mathrm{mer} h \mathrm{Tel} \mathrm{K}$ & $2.1 \times 10^{3}$ & -2.7
\end{tabular}

factor of approximately 30. Furthermore, the second binding event observed in the DMZ binding to $7 \mathrm{bp} \mathrm{HP-AT}$ is now eliminated in of the case of Triazene-1 interacting with the duplex DNA, 7bp HP-AT. Clearly, the removal of one amidine group from the parent DMZ compound to create the Triazene-1 ligand results in the loss of $\mathrm{A}_{2} \mathrm{~T}_{2}$ recognition in the minor groove of the DNA. This was expected as the presence of two amidine groups is a common feature of several minor groove binders such as distamycin, ${ }^{70}$ netropsin, ${ }^{64,66,70}$ DAPI $^{71}$ and pentamidine. ${ }^{72}$ How- $^{-}$ ever, it remains to be answered why the loss of $\mathrm{A}_{2} \mathrm{~T}_{2}$ recognition in the minor groove as exhibited by Triazene- 1 also results in much lower binding affinities for the interactions of Triazene-1 with different G-quadruplexes.

\section{DMZ binding to G quadruplexes studied by circular dichroism} (CD)

To determine the structural effects of the interactions between the DMZ and G-quadruplex DNAs, we performed a series of CD titration experiments in which DMZ was added to different G-quadruplexes. Fig. 9 and 10 show the CD spectra for the titration of DMZ into three different G-quadruplexes, $b c l-2$, $c-m y c$, and hTel22. These CD titrations were performed in $\mathrm{K}^{+}$ Tris buffer. Under these experimental buffer conditions $\left(\mathrm{K}^{+}\right.$salt), the CD spectra for the free WT bcl-2, WT c-myc, and hTel22 G-quadruplexes exhibited characteristic CD spectral features that are similar to those previously reported in the literature. ${ }^{49-51,62}$ However, upon complexation with DMZ, the CD signals for both 27 mer WT $b c l-2$ and 24mer WT $c$-myc dramatically attenuated as DMZ is added. A plausible explanation for this is that the inherent G-tetrad $\pi-\pi$ stacking interactions in both the $27 \mathrm{mer}$ WT $b c l-2$ and 24mer WT c-myc G-quadruplexes is weakened upon DMZ binding. In comparison to TMyP4, DMZ does not have the extended $\pi$-surfaces, which can interact extensively with the $\pi$ system of the G-tetrad in either an end-stacking or intercalation mode. Perhaps the explanation for the surprisingly tight binding to specific G-quadruplexes is that DMZ is binding in the G-quadruplex groove or interacting in some way with loop bases. In the case of DMZ binding to $\mathrm{K}^{+} h$ Tel22, the addition of the 

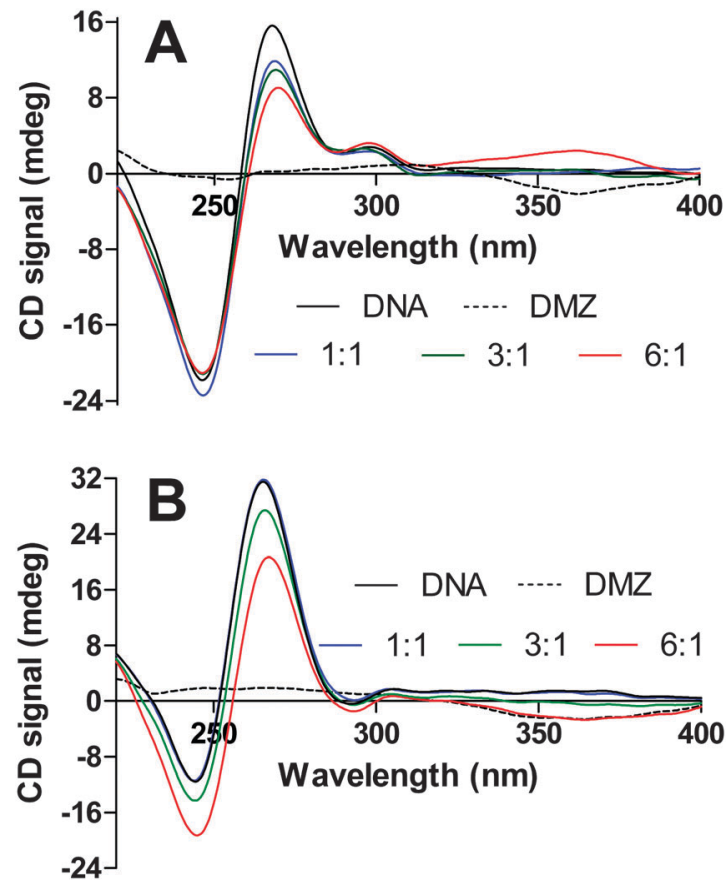

Fig. $9 \mathrm{CD}$ spectra obtained from titration experiments for the additions of DMZ into a $27 m e r$ WT bcl-2 (4.5 $\mu \mathrm{M}$, panel A) and into 24 mer WT c-myc (3.9 $\mu \mathrm{M}$, panel B).

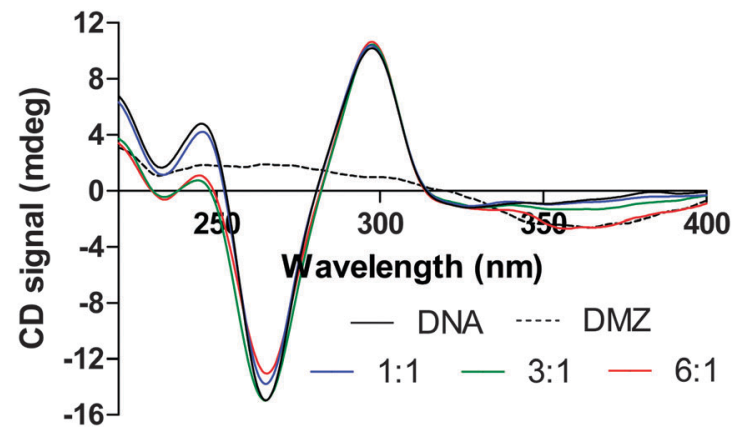

Fig. $10 C D$ spectra obtained from titration experiment for the additions of DMZ into a $h$ Tel22 $(5.1 \mu \mathrm{M})$.

DMZ appears to have very little effect on the parallel structure of hTel22 G-quadruplex, see Fig. 10. In the case of binding DMZ to duplex DNA, an induced DMZ CD signal is observed (see Fig. S6, $\mathrm{ESI} \dagger$ ). However, there was no evidence for an induced ligand CD signal when DMZ was bound to the different G-quadruplexes. This lack of an induced CD is suggestive of end stacking or intercalative binding but not groove binding. ${ }^{73}$ A more detailed structural study of the DMZ G-quadruplex complexes could clarify these observations and help in the development of even more potent DMZ-based G-quadruplex binders.

\section{Conclusion}

The finding that DMZ binds tightly to G-quadruplexes DNA is exciting for the following reasons: (a) DMZ does not readily form $\pi$-aggregates ${ }^{74}$ and hence it is not as prone to non-specific binding to other biomolecules as other aromatic-containing G-quadruplex ligands; (b) the amidine groups on DMZ, improve aqueous solubility (an important factor for drugs); (c) unlike other structurally complex minor groove binders such as netropsin, DMZ has a simple structure and could be readily diversified and synthesized cheaply on a large scale and (d) the amidine group, which is protonated at physiological $\mathrm{pH}$, would facilitate drug permeation across lipid membranes that are externally decorated with anionic phosphates.

This work suggests that some of the toxicity or even the clinical benefits of $\mathrm{DMZ}$ may be due to its binding to G-quadruplexes, which has so far been overlooked. It is ironic that a ligand such as DMZ, which has long been considered as AT-rich specific minor groove binder does in fact strongly bind to G-quadruplexes. Future work will concentrate on making structural variants of DMZ that will include expanded aromatic systems and increased amidine groups for specific and potent G-quadruplex targeting. New classes of G-quadruplex ligands, which have low affinity for duplex DNA, are predicted to have potential applications in cancer therapy. ${ }^{75-77}$

\section{Acknowledgements}

Camille Dreyfus foundation and University of Maryland Graduate Dean's Dissertation Fellowship (JZ) supported this work.

\section{References}

1 M. Gellert, M. N. Lipsett and D. R. Davies, Proc. Natl. Acad. Sci. U. S. A., 1962, 48, 2013.

2 M. L. Bochman, K. Paeschke and V. A. Zakian, Nat. Rev. Genet., 2012, 13, 770.

3 S. Kumari, A. Bugaut, J. L. Huppert and S. Balasubramanian, Nat. Chem. Biol., 2007, 3, 218.

4 M. D. Frank-Kamenetskii and S. M. Mirkin, Annu. Rev. Biochem., 1995, 64, 65.

5 V. Sklenar and J. Feigon, Nature, 1990, 345, 836.

6 K. Gehring, J. L. Leroy and M. Gueron, Nature, 1993, 363, 561 .

7 T. A. Brooks, S. Kendrick and L. Hurley, FEBS J., 2010, 277, 3459.

8 G. W. Collie and G. N. Parkinson, Chem. Soc. Rev., 2011, 40, 5867.

9 M. Duchler, J. Drug Targeting, 2012, 20, 389.

10 S. Balasubramanian, L. H. Hurley and S. Neidle, Nat. Rev. Drug Discovery, 2011, 10, 261.

11 A. K. Todd, M. Johnston and S. Neidle, Nucleic Acids Res., 2005, 33, 2901.

12 J. L. Huppert and S. Balasubramanian, Nucleic Acids Res., 2005, 33, 2908.

13 Y. Xu, Chem. Soc. Rev., 2011, 40, 2719.

14 M. Wieland and J. S. Hartig, Chem. Biol., 2007, 14, 757.

15 M. Wieland and J. S. Hartig, Nat. Protoc., 2009, 4, 1632. 
16 J. D. Beaudoin and J. P. Perreault, Nucleic Acids Res., 2010, 38, 7022 .

17 J. Alzeer, B. R. Vummidi, P. J. Roth and N. W. Luedtke, Angew. Chem., Int. Ed., 2009, 48, 9362.

18 Q. Yang, J. Xiang, S. Yang, Q. Zhou, Q. Li, Y. Tang and G. Xu, Chem. Commun., 2009, 1103.

19 C. Schaffitzel, I. Berger, J. Postberg, J. Hanes, H. J. Lipps and A. Pluckthun, Proc. Natl. Acad. Sci. U. S. A., 2001, 98, 8572.

20 G. Biffi, D. Tannahill, J. McCafferty and S. Balasubramanian, Nat. Chem., 2013, 5, 182.

21 P. Agrawal, E. Hatzakis, K. Guo, M. Carver and D. Yang, Nucleic Acids Res., 2013, 41, 10584.

22 W. J. Chung, B. Heddi, M. Tera, K. Iida, K. Nagasawa and A. T. Phan, J. Am. Chem. Soc., 2013, 135, 13495.

23 I. T. Holder, M. Drescher and J. S. Hartig, Bioorg. Med. Chem., 2013, 21, 6156.

24 M. Azarkh, V. Singh, O. Okle, D. R. Dietrich, J. S. Hartig and M. Drescher, ChemPhysChem, 2012, 13, 1444.

25 N. W. Kim, M. A. Piatyszek, K. R. Prowse, C. B. Harley, M. D. West, P. L. Ho, G. M. Coviello, W. E. Wright, S. L. Weinrich and J. W. Shay, Science, 1994, 266, 2011.

26 A. M. Zahler, J. R. Williamson, T. R. Cech and D. M. Prescott, Nature, 1991, 350, 718.

27 Y. Wang and D. J. Patel, Structure, 1993, 1, 263.

28 G. N. Parkinson, M. P. Lee and S. Neidle, Nature, 2002, 417, 876.

29 G. W. Collie, S. M. Haider, S. Neidle and G. N. Parkinson, Nucleic Acids Res., 2010, 38, 5569.

30 C. Bazzicalupi, M. Ferraroni, A. R. Bilia, F. Scheggi and P. Gratteri, Nucleic Acids Res., 2013, 41, 632.

31 Q. Li, J. F. Xiang, H. Zhang and Y. L. Tang, Curr. Pharm. Des., 2012, 18, 1973.

32 T. Vy Thi Le, S. Han, J. Chae and H. J. Park, Curr. Pharm. Des., 2012, 18, 1948.

33 I. Mender, S. Senturk, N. Ozgunes, K. C. Akcali, D. Kletsas, S. Gryaznov, A. Can, J. W. Shay and Z. G. Dikmen, Int. J. Oncol., 2013, 42, 1709.

34 S. M. Gowan, J. R. Harrison, L. Patterson, M. Valenti, M. A. Read, S. Neidle and L. R. Kelland, Mol. Pharmacol., 2002, 61, 1154.

35 J. I. Roh, Y. H. Sung and H. W. Lee, OncoTargets Ther., 2013, 6, 1161.

36 A. Siddiqui-Jain, C. L. Grand, D. J. Bearss and L. H. Hurley, Proc. Natl. Acad. Sci. U. S. A., 2002, 99, 11593.

37 J. Dai, T. S. Dexheimer, D. Chen, M. Carver, A. Ambrus, R. A. Jones and D. Yang, J. Am. Chem. Soc., 2006, 128, 1096.

38 S. Cogoi and L. E. Xodo, Nucleic Acids Res., 2006, 34, 2536.

39 S. Rankin, A. P. Reszka, J. Huppert, M. Zloh, G. N. Parkinson, A. K. Todd, S. Ladame, S. Balasubramanian and S. Neidle, J. Am. Chem. Soc., 2005, 127, 10584.

40 D. Sun, W. J. Liu, K. Guo, J. J. Rusche, S. Ebbinghaus, V. Gokhale and L. H. Hurley, Mol. Cancer Ther., 2008, 7, 880.

41 M. Gunaratnam, S. Swank, S. M. Haider, K. Galesa, A. P. Reszka, M. Beltran, F. Cuenca, J. A. Fletcher and S. Neidle, J. Med. Chem., 2009, 52, 3774.
42 K. I. McLuckie, Z. A. Waller, D. A. Sanders, D. Alves, R. Rodriguez, J. Dash, G. J. McKenzie, A. R. Venkitaraman and S. Balasubramanian, J. Am. Chem. Soc., 2011, 133, 2658.

43 R. Martinez and L. Chacon-Garcia, Curr. Med. Chem., 2005, $12,127$.

44 T. M. Ou, Y. J. Lu, J. H. Tan, Z. S. Huang, K. Y. Wong and L. Q. Gu, ChemMedChem, 2008, 3, 690.

45 W. I. Sundquist and S. Heaphy, Proc. Natl. Acad. Sci. U. S. A., 1993, 90, 3393.

46 Q. Yang, J. Xiang, S. Yang, Q. Li, Q. Zhou, A. Guan, X. Zhang, H. Zhang, Y. Tang and G. Xu, Nucleic Acids Res., 2010, 38, 1022.

47 V. H. Le, R. Buscaglia, J. B. Chaires and E. A. Lewis, Anal. Biochem., 2013, 434, 233.

48 G. E. Plum, Current Protocols in Nucleic Acid Chemistry, 2001, ch. 7, unit 7.3 , DOI: 10.1002/0471142700.nc0703s00.

49 N. Nagesh, R. Buscaglia, J. M. Dettler and E. A. Lewis, Biophys. J., 2010, 98, 2628.

50 J. M. Dettler, R. Buscaglia, V. H. Le and E. A. Lewis, Biophys. J., 2011, 100, 1517.

51 J. S. Hudson, L. Ding, V. Le, E. Lewis and D. Graves, Biochemistry, 2014, 53, 3347.

52 Z. Dong, S. Ekins and J. E. Polli, Mol. Pharmaceutics, 2013, 10, 1008.

53 P. B. Madrid, S. Chopra, I. D. Manger, L. Gilfillan, T. R. Keepers, A. C. Shurtleff, C. E. Green, L. V. Iyer, H. H. Dilks, R. A. Davey, A. A. Kolokoltsov, R. Carrion, Jr., J. L. Patterson, S. Bavari, R. G. Panchal, T. K. Warren, J. B. Wells, W. H. Moos, R. L. Burke and M. J. Tanga, PLoS One, 2013, 8, e60579.

54 S. Cosconati, L. Marinelli, R. Trotta, A. Virno, S. De Tito, R. Romagnoli, B. Pagano, V. Limongelli, C. Giancola, P. G. Baraldi, L. Mayol, E. Novellino and A. Randazzo, J. Am. Chem. Soc., 2010, 132, 6425.

55 S. Cosconati, A. Rizzo, R. Trotta, B. Pagano, S. Iachettini, S. De Tito, I. Lauri, I. Fotticchia, M. Giustiniano, L. Marinelli, C. Giancola, E. Novellino, A. Biroccio and A. Randazzo, J. Med. Chem., 2012, 55, 9785.

56 L. Martino, A. Virno, B. Pagano, A. Virgilio, S. Di Micco, A. Galeone, C. Giancola, G. Bifulco, L. Mayol and A. Randazzo, J. Am. Chem. Soc., 2007, 129, 16048.

57 A. K. Jain and S. Bhattacharya, Bioconjugate Chem., 2011, 22, 2355.

58 M. P. Barrett, C. G. Gemmell and C. J. Suckling, Pharmacol. Ther., 2013, 139, 12.

59 I. Kelsey, S. Nakayama and H. O. Sintim, Bioorg. Med. Chem. Lett., 2012, 22, 881.

60 D. G. Brown, M. R. Sanderson, J. V. Skelly, T. C. Jenkins, T. Brown, E. Garman, D. I. Stuart and S. Neidle, EMBO J., 1990, 9, 1329.

61 W. W. Hartman and T. B. Dickey, Org. Synth., 1934, 24.

62 V. H. Le, N. Nagesh and E. A. Lewis, PLoS One, 2013, 8, e72462.

63 G. B. Rowland, K. Barnett, J. I. Dupont, G. Akurathi, V. H. Le and E. A. Lewis, Bioorg. Med. Chem., 2013, 21, 7515.

64 M. W. Freyer, R. Buscaglia, D. Cashman, S. Hyslop, W. D. Wilson, J. B. Chaires and E. A. Lewis, Biophys. Chem., 2007, 126, 186. 
65 M. W. Freyer, R. Buscaglia, B. Nguyen, W. D. Wilson and E. A. Lewis, Anal. Biochem., 2006, 355, 259.

66 M. W. Freyer, R. Buscaglia, A. Hollingsworth, J. Ramos, M. Blynn, R. Pratt, W. D. Wilson and E. A. Lewis, Biophys. J., 2007, 92, 2516.

67 E. A. Lewis, M. Munde, S. Wang, M. Rettig, V. Le, V. Machha and W. D. Wilson, Nucleic Acids Res., 2011, 39, 9649.

68 M. W. Freyer, R. Buscaglia, K. Kaplan, D. Cashman, L. H. Hurley and E. A. Lewis, Biophys. J., 2007, 92, 2007.

69 T. Jenkins, A. Lane, S. Neidle and D. Brown, Eur. J. Biochem., 1993, 213, 1175.

70 M. L. Kopka, C. Yoon, D. Goodsell, P. Pjura and R. E. Dickerson, Proc. Natl. Acad. Sci. U. S. A., 1985, 82, 1376.
71 W. Wilson, F. Tanious, H. Barton, L. Strekowski, D. Boykin and R. Jones, J. Am. Chem. Soc., 1989, 111, 5008.

72 I. Donkor, R. Tidwell and S. Jones, J. Med. Chem., 1994, 37, 4554.

73 M. Carvlin, N. Dattagupta and R. Fiel, Biochem. Biophys. Res. Commun., 1982, 108, 66.

74 D. S. Pilch, M. A. Kirolos, X. Liu, G. E. Plum and K. J. Breslauer, Biochemistry, 1995, 34, 9962.

75 R. Haudecoeur, L. Stefan, F. Denat and D. Monchaud, J. Am. Chem. Soc., 2013, 135, 550.

76 O. P. Cetinkol, A. E. Engelhart, R. K. Nanjunda, W. D. Wilson and N. V. Hud, ChemBioChem, 2008, 9, 1889. 77 T. A. Brooks and L. H. Hurley, Genes Cancer, 2010, 1, 641. 